\title{
Gaseous pollutants from a small-scale aerobic biological treatment facility: odor and health risk assessment
}

\author{
Kexian $\mathrm{Li}^{1}$, Xinhong $\mathrm{Xu}^{1}$, Fan $\mathrm{Lü}^{2}$, Pinjing $\mathrm{He}^{2}$ and Jingjing Fang ${ }^{1 *}(\mathbb{C}$
}

\begin{abstract}
Background: Biological treatment technology is good for the recovery of resources and energy from municipal solid waste (MSW) and cutting down biodegradable components in landfill waste. Recently, the aerobic biological treatment of MSW has increased in rural areas of China. These facilities are usually open setup and close to nearby residents, and complaints tend to be received regarding odorous gases. A semi-in-vessel setup facility was built in recent years, and its impact on the environment and personnel is not clear.

Results: Ammonia was the predominant compound released from the windrow and its concentration was one order of magnitude higher than those of other compounds. Terpenes and reduced sulfur compounds (RSCs) persisted throughout the entire active fermentation process, with only slight decreases. The biofilter pool had a greater odor impact on the surrounding neighborhood than the waste unloading and sorting operation. The concentrations of most compounds were reduced by the biofilter pool. Ten major substances that caused odors at the facility were analyzed, where most comprised RSCs. The odor impact of the facility was low, but it was associated with a carcinogenic risk to the operators, thereby indicating the need to improve personal protection.

Conclusions: Large amounts of ammonia and volatile organic compounds were released from the composting units, but they had a low odor impact on the environment because of the semi-in-vessel setup. The odor impact of the facility was low but it was associated with a carcinogenic risk to the operators. This technology can be popularized in rural areas.
\end{abstract}

Keyword: Small scale, Aerobic biological treatment, Gaseous pollutants, Odor assessment, Carcinogenic risk assessment

\section{Background}

Biological treatment technology is good for the recovery of resources and energy from municipal solid waste (MSW) and cutting down biodegradable components in landfill waste. Recently, the aerobic biological treatment of MSW has increased in rural areas of China. These facilities are usually close to nearby residents, and complaints tend to be received regarding odorous

\footnotetext{
*Correspondence: 5524217745@qq.com

${ }^{1}$ Navy Medical Centre, Second Military Medical University, 880 Xiangyin

Road, Shanghai 200433, China

Full list of author information is available at the end of the article
}

gases. Ammonia is the predominant gaseous pollutant with emissions of around $18-1150 \mathrm{~g} / \mathrm{t}$ waste [1]. Composting technology is one of the important methods for organic waste disposal. Windrow composting and trough composting are two main technology in China. Most of Windrow composting got lower $\mathrm{H}_{2} \mathrm{~S}$ emission, but higher $\mathrm{NH}_{3}$ release comparing with trough composting [2]. The concentration of ammonia in the exhaust gas from sludge composting facilities can be as high as can be as high as $700 \mathrm{mg} / \mathrm{m}^{3}$ [3]. Volatile organic compounds (VOCs) are also one of typical air pollutants, with concentrations in the air around MSW composting facilities ranging from 8 to $16 \mathrm{mg} / \mathrm{m}^{3}$ [4]. Rodriguez et al. [5] researched the 
influence of the operating technology to VOC release, such as moisture, oxygen, and $\mathrm{C}: \mathrm{N}$ ratios (ratio of carbon to nitrogen). They found that the most important factor was the $\mathrm{C}: \mathrm{N}$ ratio, then was the internal oxygen and moisture contents of the windrow.

The emission patterns of gaseous pollutants during mechanical processes, such as waste sorting and shredding, differ significantly from those in aerobic biological treatment processes. Stirring and crushing processes can strip some compounds, especially xenobiotic organics, from the surface of the waste and make them readily volatilized [6]. Toluene and xylene are the dominant VOCs in the shredding, mixing, and sorting areas of composting facilities. Some studies reported that these aromatics originated from the decomposition of polymer and solvents [7], whereas others have shown that these aromatics compounds are released from raw materials rather than intermediate products of waste biodegradation. Volatile fatty acids (VFAs) can be produced by the hydrolysis and anaerobic digestion of carbohydrates [8, 9], fats, and proteins in waste, and they can accumulate when inadequate oxygen is supplied during aerobic biodegradation [10]. The olfactory threshold of VFAs is low, which has a great impact on the environment.

Sulfur compounds, nitrogen-containing compounds and terpenes have strong pungent odor also, so the emission of these gas pollutants will have odor impact on nearby communities. In the process of refuse composting, incomplete or inadequate ventilation will lead to the release of hydrogen sulfide and other malodorous substances [11, 12]. Fang et al. [13] found that limonene, dimethyl sulfide, dimethyl disulfide and $\alpha$-pinene are the main odorants in municipal solid waste composting facilities. Tsai et al. [14] studied the kitchen waste composting facilities and found that the concentrations of ammonia, dimethyl sulfide and hydrogen sulfide had a logarithmic relationship with odor intensity, while the concentrations of ethylbenzene, acetic acid and p-toluene had a linear relationship with odor intensity. This result tells us that reducing odor intensity of ammonia, dimethyl sulfide and hydrogen sulfide is much more difficult than other pollutants. It is reported that the odor of trimethylamine has high persistence and low odor threshold. Therefore, if the odor source contains trimethylamine, the influence range and distance of the source are larger than others [15].

The present study investigated the odor compounds emitted from a small-scale MSW aerobic biological treatment facility as well as assessing the odor impact and health risk for the operators. Based on the theoretical odor concentrations and exposure concentrations, the main odor compounds were identified in various treatment processes, as well as the hazard quotient and carcinogenic risk was evaluated.

\section{Methods \\ Site description and sampling location}

The study site was located in Shanghai Chong Ming Island, with a capacity of approximately $0.6-2$ ton/day, and the service area comprising a community of 4000 resident was $100 \mathrm{~m}$ away from the facility. The facility comprised 20 composting units, a biofilter pool, and a sorting area, as shown in Fig. 1. The facility was opened except the composting unit and the board was not walls but railing. The composting unit was usually closed only when the waste feeding opened. Oxygen was supplied through the ventilation system in the bottom and the gas was collected for purification through the biofilter system. Chopped straw with a length of $2-5 \mathrm{~cm}$ was used

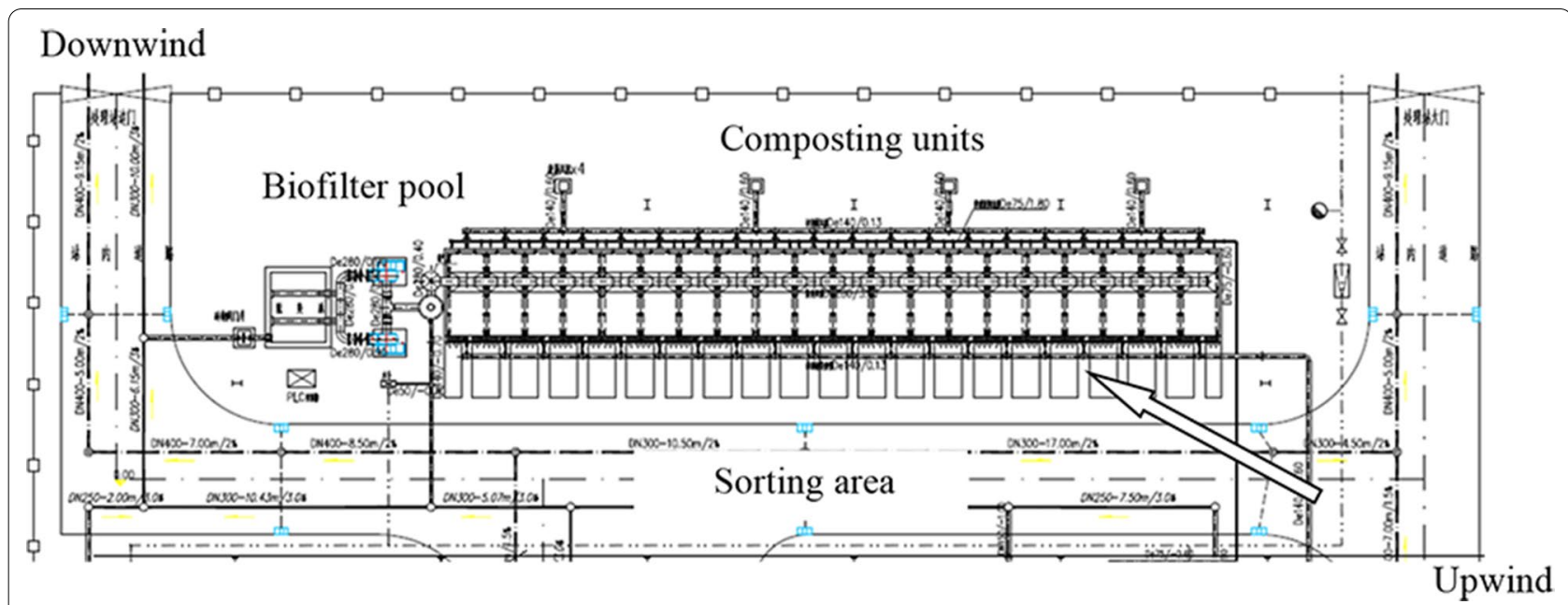

Fig. 1 Schematic diagram of the aerobic biological treatment facility 
as a bulking agent. After removing glass and metal debris, the raw MSW was mixed with the bulking agent at a ratio of $10: 1(\mathrm{w} / \mathrm{w})$ considering that the water content should not be excessively low, and an adequate specific surface area and free air spaces were necessary in the matrix [16]. The characteristics of the raw materials and mixture are presented in Table 1. The volatile solids content was analyzed by heating samples to a constant weight at $550{ }^{\circ} \mathrm{C}$ in a muffle furnace. The oxygen concentration and temperature at the core of the windrow were monitored using a probe (CYS-1; Xuelian Co., Shanghai, China). The elemental compositions of the freeze-dried samples were measured using an elemental analyzer (Vario EL III, Elementar Analysensysteme GmbH, Langenselbold, Germany). Active fermentation (static composting-like process) occurred for 20 days in the closed composting unit with controlled aeration and gas collection, as well as treatment with a biofilter.

Odorous gas sampling was conducted during waste loading, unloading, and sorting. Three sampling points were located in the sorting area, and upwind and downwind of the boundary of the facility. Sampling was also conducted at the same points when the facility was not in operation in order to conduct comparisons. One point was located in the biofilter pool when the ventilation process started. Inside the composting units, gas and solid sampling were conducted after $1,3,5,7,10,15$, and

Table 1 Characteristics of the raw materials and mixture feedstock in the tested composting unit

\begin{tabular}{lllll}
\hline & MSW & Straw & Mixture $^{\mathbf{a}}$ & Mixture $^{\mathbf{b}}$ \\
\hline $\begin{array}{l}\text { Water content, \% by wet } \\
\text { mass }\end{array}$ & $74.4 \pm 2.7$ & $8.72 \pm 0.45$ & $70.7 \pm 1.3$ & 68.4 \\
VS, \% by dry mass & $79.7 \pm 1.6$ & $88.6 \pm 0.3$ & $84.3 \pm 1.1$ & 86.3 \\
C:N ratio by dry mass & $20.5 \pm 1.8$ & $41.5 \pm 2.4$ & $17.1 \pm 2.9$ & 17.8 \\
$\begin{array}{l}\text { Proportion (wet mass, } \\
\text { W/W) }\end{array}$ & $10 / 11$ & $1 / 11$ & - & - \\
Weight (wet mass, kg) & 550 & 55 & 605 & 605 \\
\hline
\end{tabular}

${ }^{a}$ The value was based on determination

${ }^{\mathrm{b}}$ The value was based on calculation
20 days during the active fermentation phase. The wind speed during the sampling period was $3.1-3.6 \mathrm{~m} / \mathrm{s}$ and the temperature was $20-24{ }^{\circ} \mathrm{C}$. The relative humidity was approximately $55-65 \%$. In total, seven chemical classes and 51 substances were determined in the gas samples, including ammonia, reduced sulfur compounds (RSCs), aromatics, terpenes, alcohols, carbonyl compounds, and VFAs.

\section{Analysis of gas samples}

Several methods were used to test different target gaseous pollutants, as showing in Table 2. These methods included sorbent concentration, cold trap concentration, derivatization concentration, gas chromatography method, liquid chromatography and colorimetric method.

\section{Analysis of ammonia using colorimetric tubes}

Ammonia in each sample was detected by colorimetric tubes (GV-100 s, GasTec., Kanagawa, Japan). Cut both ends of the colorimetric tube and insert the colorimetric tube into the hand pump in the direction of the arrow. A specific volume of $100 \mathrm{ml}$ gas was extracted to the colorimetric tubes. Wait several minutes and confirm the completion of the sampling. The lengths of the color changes in the tubes indicated the concentrations of ammonia.

\section{GC analysis after cold trap concentration}

The air samples were collected by Tedlar bags (3L, SKC, PA, USA) which were placed in a sealed plastic box. There were two holes on the lid of the plastic box, one was connected with the Tedlar bag, and the other was connected with a vacuum pump. When the box was vacuumized by the pump, the air sample entered to the Tedlar bag through the hole connected with the bag. This will prevent the air pump from contaminating the air samples. The samples were placed for dark storage and transported to the laboratory within $12 \mathrm{~h}$ to minimize the loss of RSCs during storage.

According to the United States Environmental Protection Agency (USEPA) TO14A method [17], these air

Table 2 Methods were used to measure different target gaseous pollutants

\begin{tabular}{lll}
\hline $\begin{array}{l}\text { Pre-concentration } \\
\text { method }\end{array}$ & Test method & Target gaseous pollutants \\
\hline- & Colorimetric tube & Ammonia \\
Sorbent & Gas chromatography with flame ionization detection (GC-FID) & Volatile fatty acids (VFAs) \\
Cold trap & Gas chromatography with flame ionization detection (GC-FID) & Aromatics, terpenes, alcohols \\
Cold trap & Gas chromatography with pulsed flame photometric detection (GC-PFPD) & Reduced sulfur compounds (RSCs) \\
Derivatization & High-performance liquid chromatography (HPLC) & Carbonyl compounds \\
\hline
\end{tabular}


samples were concentrated by cold trap (Entech Instruments Inc., CA, USA) with liquid nitrogen, then detected by GC-FID and GC-PFPD (GC 450, Varian Inc., CA, USA). The injection volume was $100-1000 \mathrm{ml}$, according to the actual concentrations. The GC-PFPD and GC-FID parameters were described in detail in our previous study [17].

\section{GC-FID analysis after sorbent concentration}

Volatile fatty acids in air samples were determined by adsorbent concentration method. Air samples were collected using commercial adsorption tubes (silica gel tubes, SKC, PA, USA). The air flow rate was $2000 \mathrm{ml} /$ min and the collection time was $120 \mathrm{~min}$. After sampling, each tube was sealed and transported to the laboratory within $12 \mathrm{~h}$. Take out the silica gel adsorbent, put it into a 5 -ml volumetric flask and absorb it with $5 \mathrm{ml}$ deionized water. After standing for $30 \mathrm{~min}$ in an ultrasonic apparatus, the supernatant was taken out and analyzed by GCFID. The operation parameters of FID detection system were the same as our previous study [18].

\section{HPLC analysis after derivation with DNPH}

Commercial cartridges (Cleanert DNPH-Silica, Agela Technology, Tianjing, China) were used to collect carbonyl compounds in the air samples. Sampling flow rate was $1000 \mathrm{ml} / \mathrm{min}$ and the sampling time was $2 \mathrm{~h}$ according to EPA method TO11A [19]. After collection, the cartridges were sealed and transported to the laboratory within $12 \mathrm{~h}$. The derived compounds in the cartridges were eluted into a 5 - $\mathrm{ml}$ volumetric flask with $5 \mathrm{ml}$ acetonitrile through a solid-phase extraction vacuum manifold (Visiprep, Supelco Analytical, Darmstadt, Germany).

A working standard calibration curve was prepared from serial dilutions of the aldehyde/ketone-DNPH standard stock solution (Cerilliant Inc., USA). The concentrations of the standard mix solutions varied from 0.075 to $15 \mathrm{ppm}$. The standard solutions and sample eluates were analyzed by HPLC (Agilent 1200, Agilent Inc., USA) attached to a diode-array detector (DAD) through an auto-sampler with a detector that was operated at $365 \mathrm{~nm}$. The detection limit of this method was $50 \mathrm{ppb}$. The analytical column used was a C18 $(4.6 \mathrm{~mm}$ ID $\times 25 \mathrm{~cm}, 5 \mu \mathrm{m}$ ) stainless steel tube (Venusil XBP, Agela Technology, China) and the mobile phase was acetonitrile (Merck, Germany) and high purity water (Milli-Q Millipore, USA). The elution program was 45\% acetonitrile for $1 \mathrm{~min}$, followed by a linear gradient from 45 to $75 \%$ acetonitrile in $30 \mathrm{~min}$, which was then held for $5 \mathrm{~min}$. The flow rate was $2 \mathrm{ml} / \mathrm{min}$ and the sample injection volume was $25 \mu$ l.

\section{Quality assurance and control}

Five levels of mixed standard gases $(50,200,400,800$, $1600 \mu \mathrm{g} / \mathrm{m}^{3}$, Air Liquid, France) were determined to produce the standard calibration curves. Within the range of $0-1600 \mu \mathrm{g} / \mathrm{m}^{3}$, the correlation was good $\left(R^{2}>0.93\right)$. The detection limit of the instrument is determined by extrapolation of the linear ratio between the minimum peak area and the instrument noise. The concentration of the blank sample was less than $1 \mu \mathrm{g} / \mathrm{m}^{3}$, indicating that there was no sample contamination during collection, transportation and storage. Ten kinds of repetitive standard gases were determined to evaluate their reproducibility. The relative standard deviation is less than $7 \%$. The standard recoveries of these methods ranged from 81 to $114 \%$.

\section{Theoretical odor concentrations}

Odor threshold concentration of each compound varies greatly and gases with high concentrations do not always contribute strong odors. Odor intensity can be measured by the ratio of its concentration and the odor threshold. When the composition of the odorous gas mixture is known, the theoretical odor concentration $\left(C_{\text {od }}\right)$ of each sample can be estimated based on its analytical concentration and odor threshold according to Eqs. (1) and (2) [20]. The odor intensity of different sample points can be compared by this method:

$$
\begin{gathered}
C_{\text {od }, i}=\frac{C_{i}}{\mathrm{OT}_{i}}, \\
C_{\text {od }}=\sum_{i=1}^{n} \frac{C_{i}}{\mathrm{OT}_{i}},
\end{gathered}
$$

where $C_{i}$ is the analytical concentration of the $i$ th compound (ppm); $\mathrm{OT}_{i}$ is the odor threshold value of the $i$ th compound $(\mathrm{ppm})$, where the $\mathrm{OT}_{\mathrm{i}}$ value for each compound was obtained from a previous study [17]; $\mathrm{C}_{\mathrm{od}, i}$ is defined as the theoretical odor concentration (dimensionless); $n$ is the total number of odorous compounds; and $C_{\text {od }}$ is the sum of the theoretical odor concentrations of $n$ compounds of one sample.

\section{Health risk assessment Carcinogenic risk assessment}

According to the Integrated Risk Information System of the United States EPA, the carcinogenic risks of gaseous pollutants were evaluated according to the inhalation unit risk (IUR) of carcinogens [21]. The cancer risk assessment was measured based on the lifetime carcinogenic risk (CRi) using Eqs. (3) and (4). The carcinogenic 
risk value for a mixed source is the sum of that for each compound, according to Eq. (5). Synergistic and antagonistic effects among substances are not considered:

$$
\begin{aligned}
& \mathrm{CRi}=\mathrm{ECi} \times \mathrm{IUR}, \\
& \mathrm{ECi}=\frac{\mathrm{Ci} \times \mathrm{ET} \times \mathrm{EF} \times \mathrm{ED}}{\mathrm{AT} \times 365 \times 24}, \\
& \mathrm{CR}=\sum_{i=1}^{n} \mathrm{CRi},
\end{aligned}
$$

where IUR is the inhalation unit risk, $\mu \mathrm{g} / \mathrm{m}^{3}$; $\mathrm{ECi}$ is the exposure concentration of each gaseous pollutant in the air, $\mu \mathrm{g} / \mathrm{m}^{3}$; $\mathrm{Ci}$ is the concentration of each gaseous pollutant in the air, $\mu \mathrm{g} / \mathrm{m}^{3}$; ET is the daily exposure time of a worker, $8 \mathrm{~h}$; EF is the exposure duration, 250 days/year; ED is the exposure duration, 30 years; and $A T$ is the average age, 70 years. The parameters were selected based on a previous study [21]. There were six workers in total. All the workers were considered as similar exposure.

\section{Non-carcinogenic risk assessment}

For non-carcinogenic risk assessment, inhalation reference concentration ( $\mathrm{RfC}$ ) was used to calculate the hazard quotient of each pollutant (HQi) by Eq. (6). The non-carcinogenic risk value for a mixed source is the sum of that for each compound, according to Eq. (7).
Synergistic and antagonistic effects among substances are not considered:

$$
\begin{aligned}
& \mathrm{HQi}=\frac{\mathrm{ECi}}{\mathrm{RfC} \times 1000 \mu \mathrm{g} / \mathrm{mg}}, \\
& \mathrm{HQ}=\sum_{i=1}^{n} \mathrm{HQi},
\end{aligned}
$$

where RfC is the inhalation reference concentration, $\mathrm{mg} / \mathrm{m}^{3}$; calculation method of ECi is the same as Eq. (4), which all values are the same except AT is the average age, 30 years. The parameters were selected based on a previous study [22].

\section{Results and discussion}

Gaseous pollutants inside the composting units

Inside the composting units, ammonia was the predominant compound and its concentration was one order of magnitude higher than that of other compounds (Fig. 2). The concentration of ammonia was $1300 \mu \mathrm{g} / \mathrm{m}^{3}$ after one day, but it increased to $35,000 \mu \mathrm{g} / \mathrm{m}^{3}$ after 5 days. After composting for 20 days, the concentration of ammonia was still $6000 \mu \mathrm{g} / \mathrm{m}^{3}$. Nitrogen in waste is readily converted into ammonia and this is more likely to occur when the C:N ratio is unbalanced. Except for ammonia, the total concentrations of the other chemical classes decreased rapidly from 8181 at the start to $224 \mu \mathrm{g} /$

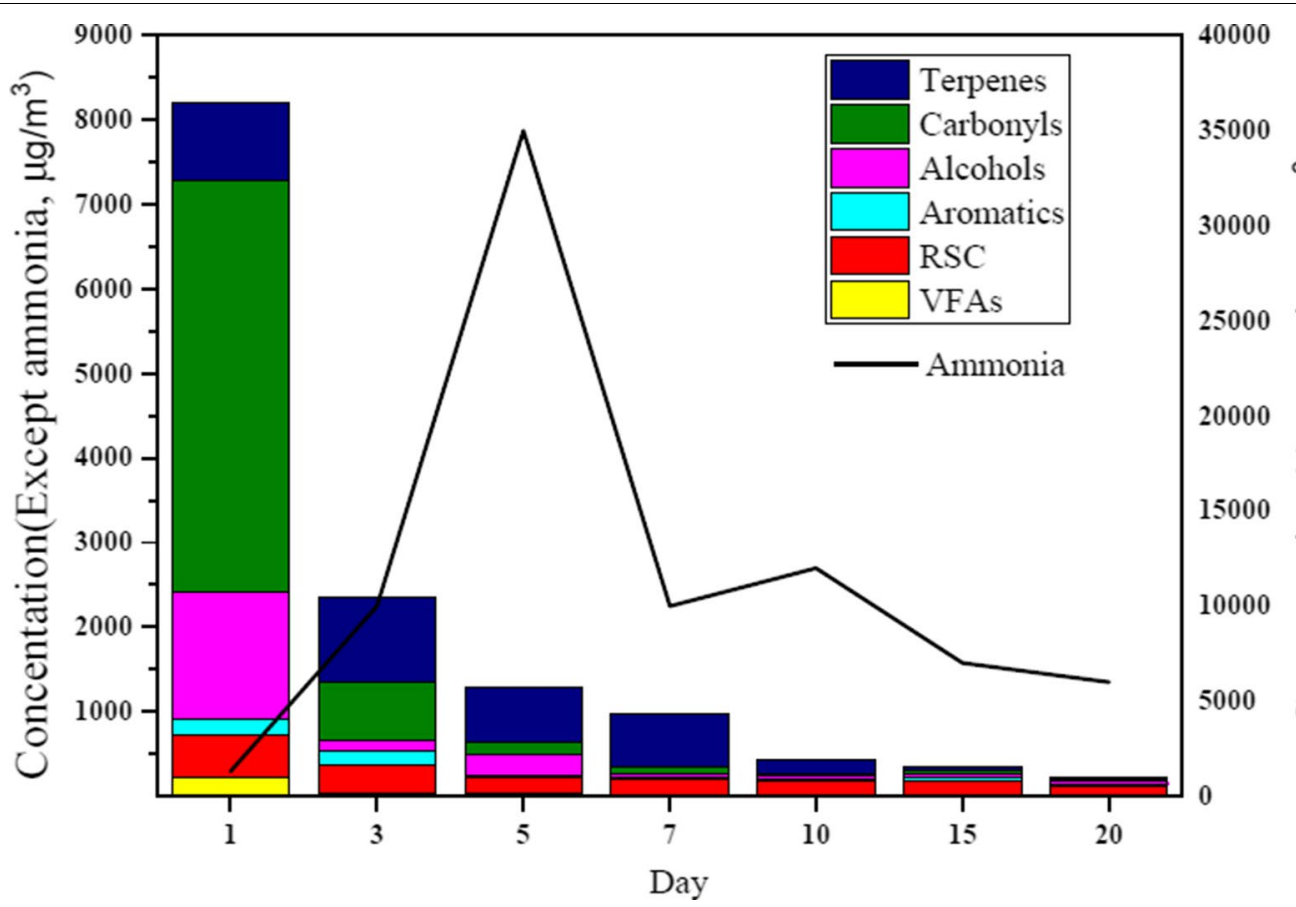

है

Fig. 2 The variation of gaseous pollutant composition with the process in the composting unit 


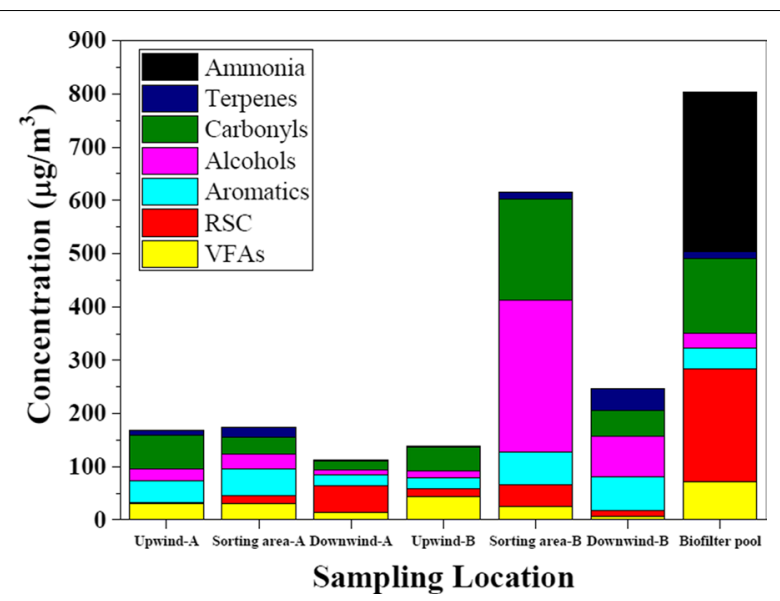

Fig. 3 Total gaseous compounds in the facility. $\mathbf{A}$ in $x$ axis represents sampling without waste unloading and sorting operation, B represents sampling during waste unloading and sorting operation $\mathrm{m}^{3}$ at the end, thereby indicating that they were mainly released at the start during the active fermentation process. In contrast to the other compounds, ammonia was mainly released in the middle stage. Terpenes and RSCs persisted throughout all stages, although their concentrations decreased slightly, whereas those of other compounds clearly decreased in the later stage.

\section{Gaseous pollutants outside the composting units}

The total contents and composition of the odor compounds outside the composting units are shown in Fig. 3 and Fig. 4, respectively. When the facility was not operating, the total concentrations upwind of the boundary, in the sorting area, and downwind of the boundary were $113 \mu \mathrm{g} / \mathrm{m}^{3}, 173 \mu \mathrm{g} / \mathrm{m}^{3}$, and $168 \mu \mathrm{g} / \mathrm{m}^{3}$, respectively. The total concentration increased when the waste unloading and sorting processes operated, with $138 \mu \mathrm{g} / \mathrm{m}^{3}$ upwind of the boundary, $615 \mu \mathrm{g} / \mathrm{m}^{3}$ in the sorting area, and $246 \mu \mathrm{g} / \mathrm{m}^{3}$ downwind of the boundary. Ammonia was
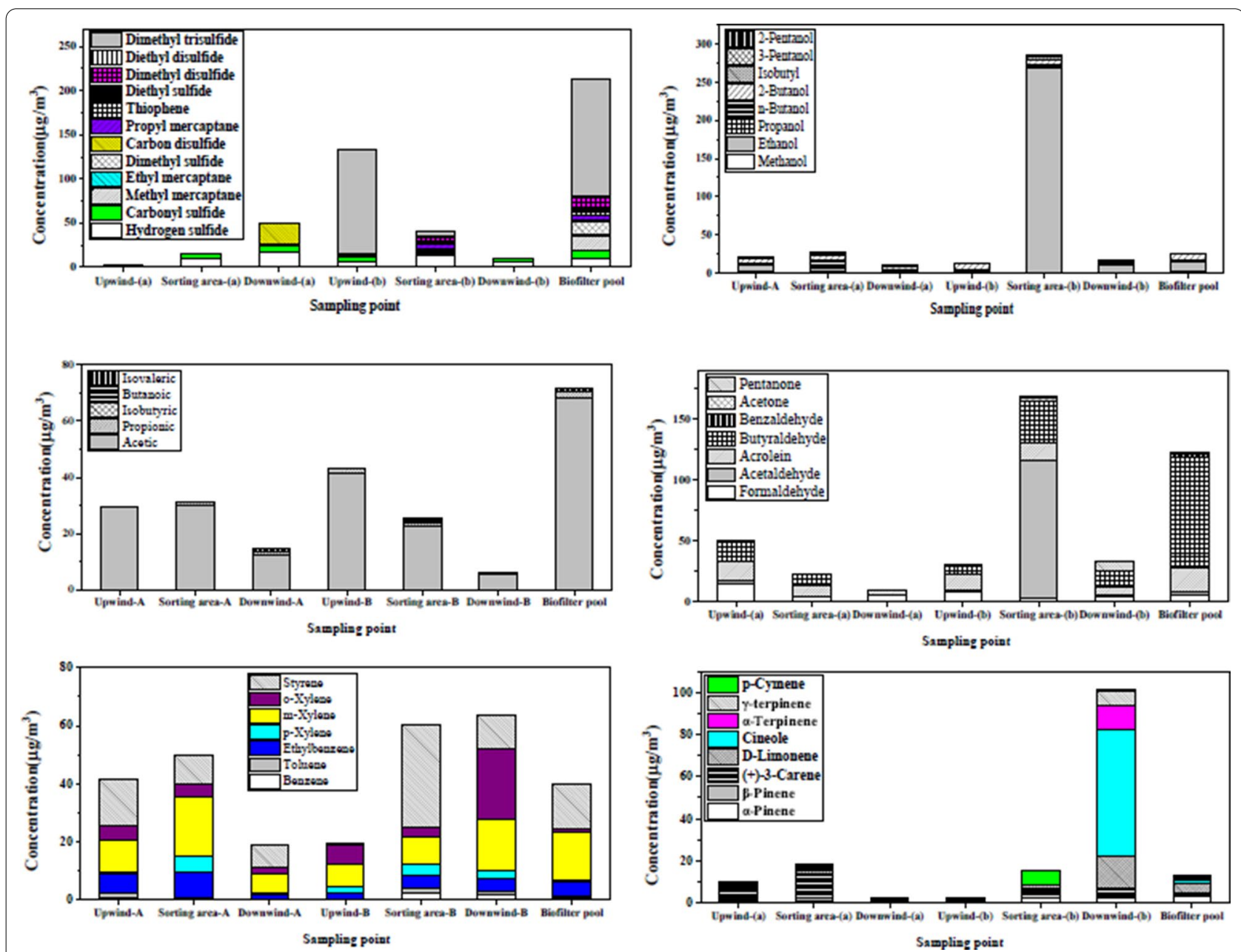

Fig. 4 Composition of the gaseous compounds in the facility. A in $x$ axis represents sampling without waste unloading and sorting operation, B represents sampling during waste unloading and sorting operation 
detected only in the biofilter pool at a concentration of $300 \mu \mathrm{g} / \mathrm{m}^{3}$. Excluding ammonia, the total concentration was $503 \mu \mathrm{g} / \mathrm{m}^{3}$ at this site. At the boundary of the facility, the concentrations of acetaldehyde, acrolein, acetic acid, and sulfur compounds (except for CS2) were higher than their olfactory thresholds. This composting facility was community scale and the treatment capacity is relatively small, about 0.6-2 ton/day. In addition to the small treatment capacity, the aerobic fermentation of this facility was carried out in closed units so the pollutant concentration was much lower than that in large plants, which was several orders of magnitude higher than this case $[13,25]$.

The concentration of total pollutants was one or two orders of magnitude higher inside the composting units than outside the units. The concentrations of most compounds were reduced by the biofilter pool, thereby demonstrating that the breakdown of the contaminants in the off-gases was effective. The concentrations of seven odor compounds on the boundary were compared with the national secondary standard limit values (as shown in Table 3 ) and they did not exceed the limit values.

\section{Major substances that caused odors of the facility}

The " $C_{\text {od }}$ " values at the facility were obtained using Eqs. (1) and (2), as shown in Fig. 5. Due to their low odor thresholds, RSCs and carbonyls were the main compounds that caused odors. The total " $C_{\text {od }}$ " value at the biofilter pool was 27,475 , which was mostly contributed by RSCs $(99.4 \%)$. The total " $C_{\text {od }}$ " value in the sorting area was 62 without operation and 2022 during operation. Downwind of the boundary, the " $C_{\text {od }}$ " values were 61 without operation and 45 during operation. The odor impact on the neighborhood during the unloading and sorting operation was very slight compared with that at the biofilter pool. Without operation,

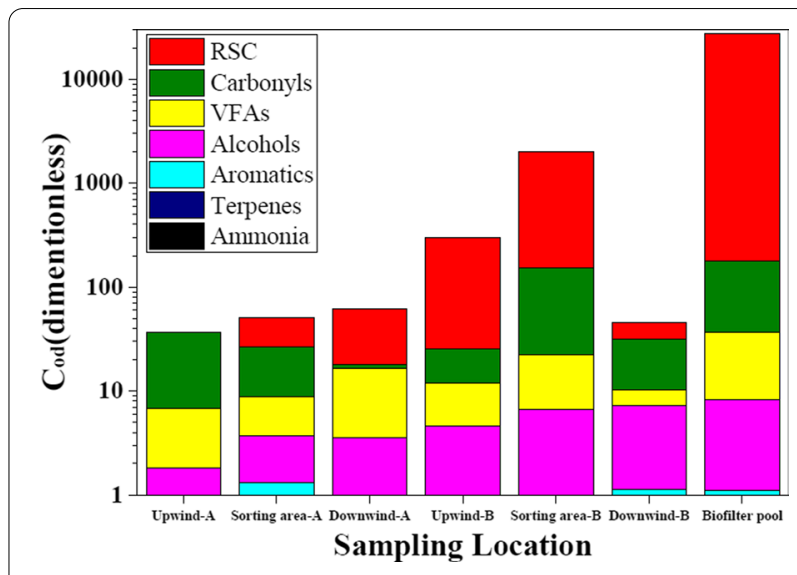

Fig. 5 Theoretical odor concentrations of the odor compounds in the facility. $\mathbf{A}$ in $x$ axis represents sampling without waste unloading and sorting operation, $\mathbf{B}$ represents sampling during waste unloading and sorting operation

the major odor substances in the sorting area were acetic acid, acrolein, hydrogen sulfide, xylene, and styrene. During operation, the major odor substances were mostly sulfur compounds, isovaleric acid, and acetaldehyde. The 10 major odor substances detected at the biofilter pool followed the order of: dimethyl trisulfide $(26,222)>$ propyl mercaptan $(425)>$ ethyl mercaptan (239) > methyl mercaptan (228) > diethyl sulfide (144) $>$ butanal (134) > hydrogen sulfide (22) > isovaleric acid (16) > acetic acid (11) > dimethyl disulfide (6). The concentrations of odor compounds such as ammonia, RSCs, alcohols, carbonyls, and VFAs were all lower at the boundary of the facility than the corresponding odor thresholds, and thus the odor risk due to the community-scale disposal facility was low for the nearby communities.

Table 3 The concentration $\left(\mu \mathrm{g} / \mathrm{m}^{3}\right)$ of odor compounds in the boundary compared with TLV and the limit value of China

\begin{tabular}{|c|c|c|c|c|c|c|}
\hline \multirow[t]{2}{*}{ Compound } & \multirow[t]{2}{*}{$\mathrm{TLV}^{\mathrm{a}}$} & \multirow[t]{2}{*}{ Limit value $^{b}$} & \multicolumn{4}{|l|}{ Location } \\
\hline & & & Upwind-A & Downwind-A & Upwind-B & Downwind-B \\
\hline Ammonia & 18,973 & 1970 & $<300$ & $<300$ & $<300$ & $<300$ \\
\hline Hydrogen sulfide & 15,178 & 37 & ND & 17.9 & 6.2 & 5.8 \\
\hline Methyl mercaptan & 1071 & 3 & ND & ND & ND & ND \\
\hline Carbon disulfide & 3392 & 884 & ND & 23.8 & ND & ND \\
\hline Dimethyl sulfide & 27,678 & 25 & ND & 1.3 & 0.9 & ND \\
\hline Dimethyl disulfide & 2098 & 15 & ND & ND & ND & ND \\
\hline Styrene & 92,857 & 1077 & 15.7 & 7.7 & 0.5 & 11.7 \\
\hline
\end{tabular}

${ }^{a}$ TLV, threshold limit value, the value was time weighted average concentration for a normal 8-h workday and reflected the level of exposure that the typical worker can experience without an unreasonable risk of disease or injury; the data come from "American Conference of Governmental Industrial Hygienists (ACGIH)"

${ }^{b}$ Limit value, Emission Standards For Odor Pollutants (China, GB 14554-93); ND, not detected; " $\mathrm{A}$ " in $x$ axis represents sampling without waste unloading and sorting operation; " $\mathrm{B}$ " represents sampling during waste unloading and sorting operation 
Table 4 Characterization of carcinogenic risk compound from inhalation exposure

\begin{tabular}{llll}
\hline Compound & Classification & Tumor site & IUR $\left(\boldsymbol{\mu g} / \mathbf{m}^{\mathbf{3}}\right)$ \\
\hline Acetaldehyde & B2 & Respiratory & $2.20 \times 10^{-6}$ \\
Benzene & A & Hematologic & $2.20 \times 10^{-6}$ \\
Formaldehyde & B1 & Respiratory & $1.30 \times 10^{-5}$
\end{tabular}

Carcinogenic classification method from weight-of-evidence of IRIS; A, carcinogenic to human; $\mathrm{B}$, possible carcinogen; $\mathrm{B} 2$, probable carcinogen; $C$, carcinogenicity to human body has not been classified; D, may not be carcinogenic

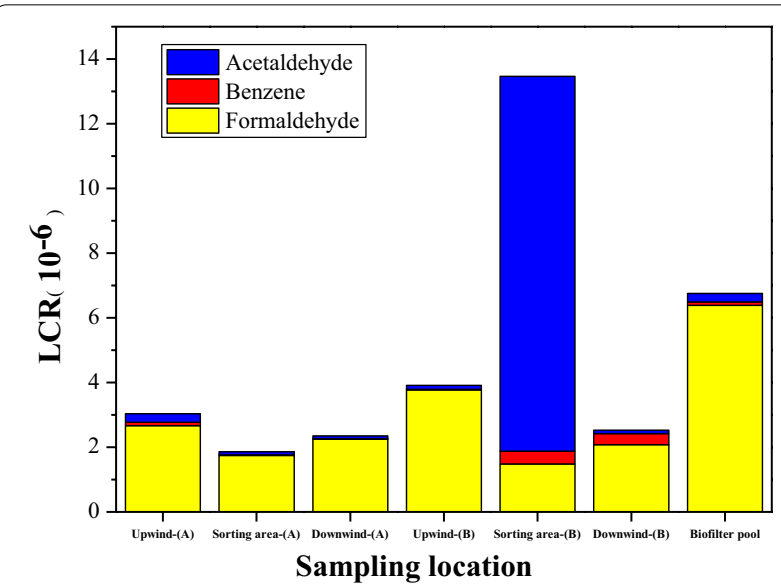

Fig. 6 Carcinogenic risks of volatile compounds through inhalation in the facility. $\mathbf{A}$ in $x$ axis represents sampling without waste unloading and sorting operation, $\mathbf{B}$ represents sampling during waste unloading and sorting operation

\section{Major substances associated with carcinogenic risk}

Gaseous pollutants emitted from waste treatment facilities may comprise a carcinogenic risk for workers due to exposure by inhalation [23-25]. Thus, three compounds were selected to evaluate the risk value. Table 4 shows the carcinogenic classifications of the three compounds used in this study to evaluate the carcinogenic risk.

The USEPA acceptable LCR level for an individual compound is $1.0 \mathrm{E}-06$. According to previous studies [22, 26], compounds with LCR values larger than $1.0 \mathrm{E}-04$ and 1.0E-03 are considered "definite risks" and "significant risks", respectively. Compounds with LCR values between $1.0 \mathrm{E}-06$ and $1.0 \mathrm{E}-05$ are considered "probable risks", and those with LCR values between 1.0E-05 and 1.0E -04 are considered "possible risks". Fig. 6 shows the LCR values obtained for the waste treatment facility, where the LCR in the facility exceeded the acceptable range of $1.0 \mathrm{E}-06$. The $\mathrm{LCR}$ value determined in the sorting area (B) indicated that the sorting operation had a possible carcinogenic risk. The main compound associated with this carcinogenic risk was acetaldehyde during the unloading and sorting operation. When the operation ended, the main compound associated with carcinogenic risk was formaldehyde. Thus, the sorting mode in this facility was a possible carcinogenic risk for the operators. Figure 6 also shows that the LCR determined for the off-gas from the biofilter pool was close to the acceptable value of $1.0 \mathrm{E}-05$. The risk may increase when the efficiency of the facility decreases.

\section{Major substances associated with non-carcinogenic risk}

Since there are workers in the facility for a long time, it is important to evaluate the non-carcinogenic risk of workers in these points. Table 5 shows the RfC value of odor compounds in this study, for evaluating non-carcinogenic risks. Altogether 13 substances were calculated in this scenario, for most of compounds in the list lack of the $R f C$ value. For non-carcinogenic risk, when the total $H Q$ was greater than 1 , the non-carcinogenic health risk level to the operators caused by these pollutants was unacceptable. When the total $H Q$ was less than 1, the non-carcinogenic health risk level to the operators was acceptable [22-26].

Figure 7 shows the non-carcinogenic risk value of the occupational exposure in the small-scale aerobic biological treatment facility. For the non-carcinogenic risk, the highest total $H Q$ was at the biofilter pool, which was 0.043 and most of it was contributed by ammonia. The total $H Q$ at all the sampling points was less than 1 , which was within an acceptable range, indicating that pollutants released from the semi-in-vessel setup facility caused little non-carcinogenic health risk to the operators. From the proportion of non-carcinogenic risk of 13 pollutants, the mainly contributed compounds were ammonia and acetaldehyde and non-carcinogenic risk of the working place was negligible.

\section{Conclusions}

In this study, ammonia was the dominant compound released from the windrow and its release occurred mainly in the middle stage, unlike most other compounds. Terpenes and RSCs persisted throughout the whole process, with slight decreases in their concentrations. Sulfur compounds, butanal, and isovaleric acid were the main compounds that caused odors at the boundary of the facility. The biofilter pool had a greater impact on the odor in the surrounding neighborhood than the waste unloading and sorting operation. Large amounts of ammonia and VOCs were released from the composting units, but they only had a small impact on the odor in the environment because of the semi-in-vessel setup. The odor impact of the facility was low but it was associated with a carcinogenic risk to the operators, thereby indicating the need to improve protection to the operators. 
Table 5 RfC values of odor compounds for calculating hazard quotients in this exposure scenario

\begin{tabular}{|c|c|c|c|c|}
\hline Family & Compound & Classification & Critical effect system & $R f C\left(\mathrm{mg} / \mathrm{m}^{3}\right)$ \\
\hline & Ammonia & - & Respiratory & $5 \times 10^{-1}$ \\
\hline \multirow[t]{5}{*}{ VFAs } & Acetic acid & - & - & - \\
\hline & Propionic acid & - & - & - \\
\hline & Isobutyric acid & - & - & - \\
\hline & Butanoic acid & - & - & - \\
\hline & Isovaleric acid & - & - & - \\
\hline \multirow[t]{8}{*}{ Alcohols } & Methanol & - & Nervous & $2 \times 10^{1}$ \\
\hline & Ethanol & - & - & - \\
\hline & Propanol & - & - & - \\
\hline & n-Butanol & - & - & - \\
\hline & 2-Butanol & - & - & - \\
\hline & Isobutanol & - & - & - \\
\hline & 3-Pentanol & - & - & - \\
\hline & 2-Pentanol & - & - & - \\
\hline \multirow[t]{7}{*}{ Aromatics } & Benzene & A & Immune(lymphocyte decreased) & $3 \times 10^{-2}$ \\
\hline & Toluene & $\mathrm{D}$ & Nervous & 5.00 \\
\hline & Ethylbenzene & D & Hepatic, urinary & 1.00 \\
\hline & p-Xylene & - & Nervous & $1.00 \times 10^{-1}$ \\
\hline & m-Xylene & - & Nervous & $1.00 \times 10^{-1}$ \\
\hline & o-Xylene & - & Nervous & $1.00 \times 10^{-1}$ \\
\hline & Styrene & - & Nervous & 1.00 \\
\hline \multirow[t]{7}{*}{ Carbonyls } & Formaldehyde & $\mathrm{B} 1$ & Squamous cell carcinomas & - \\
\hline & Acetaldehyde & B2 & Respiratory & $9 \times 10^{-3}$ \\
\hline & Acrolein & - & Respiratory and peripheral & $2 \times 10^{-5}$ \\
\hline & Butyraldehyde & - & - & - \\
\hline & Benzaldehyde & - & - & - \\
\hline & Acetone & - & - & - \\
\hline & Pentanone & - & - & - \\
\hline \multirow[t]{12}{*}{ RSCs } & Hydrogen sulfide & - & Nervous, respiratory & $2.00 \times 10^{-3}$ \\
\hline & Carbonyl sulfide & - & - & - \\
\hline & Methyl mercaptan & - & - & - \\
\hline & Ethyl mercaptan & - & - & - \\
\hline & Dimethyl sulfide & - & - & - \\
\hline & Carbon disulfide & - & Nervous(peripheral nervous system dysfunction) & $7.00 \times 10^{-1}$ \\
\hline & Propyl mercaptan & - & - & - \\
\hline & Thiophene & - & - & - \\
\hline & Diethyl sulfide & - & - & - \\
\hline & Dimethyl disulfide & - & - & - \\
\hline & Diethyl disulfide & - & - & - \\
\hline & Dimethyl trisulfide & - & - & - \\
\hline \multirow[t]{8}{*}{ Terpenes } & a-Pinene & - & - & - \\
\hline & $\beta$-Pinene & - & - & - \\
\hline & (+)-3-Carene & - & - & - \\
\hline & D-Limonene & - & - & - \\
\hline & Cineole & - & - & - \\
\hline & a-Terpinene & - & - & - \\
\hline & $\gamma$-Terpinene & - & - & - \\
\hline & p-Cymene & - & - & - \\
\hline
\end{tabular}




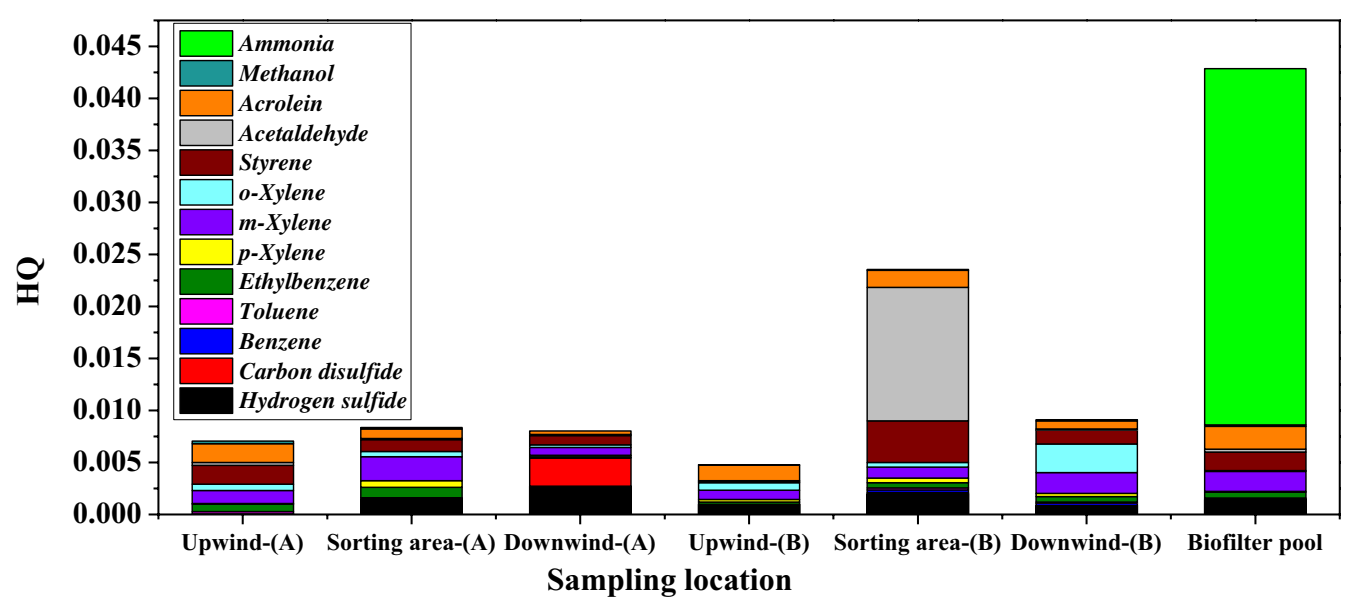

Fig. 7 Non-carcinogenic risks of volatile compounds through inhalation in the facility. A in $x$ axis represents sampling without waste unloading and sorting operation, $\mathbf{B}$ represents sampling during waste unloading and sorting operation

\section{Acknowledgements}

\section{Not applicable.}

\section{Authors' contributions}

KL was responsible for interpreting results, updating reference lists and creating 'Summary of findings' tables. XX was responsible for writing the paper. JF was responsible for conducting the search. Pinjing He was responsible for screening potentially eligible studies, extracting and analyzing data. FL was responsible for extracting and analyzing data and interpreting results. All authors read and approved the final manuscript.

\section{Funding}

This research was funded by the Navy Foundation of China, National Natural Science Foundation of China (No. 21507161).

\section{Availability of data and materials}

Not applicable.

\section{Declarations}

Ethics approval and consent to participate

Not applicable.

\section{Consent for publication}

Not applicable.

\section{Competing interests}

The authors declare that they have no competing interests.

\section{Author details}

${ }^{1}$ Navy Medical Centre, Second Military Medical University, 880 Xiangyin Road, Shanghai 200433, China. ${ }^{2}$ College of Environmental Science and Engineering, Tongji University, 1239 Siping Road, Shanghai 200092, China.

Received: 15 August 2021 Accepted: 23 October 2021

Published online: 10 November 2021

\section{References}

1. Clemens J, Cuhls C (2003) Greenhouse gas emissions from mechanical and biological waste treatment of municipal waste. Environ Technol 24(6):745-754
2. Xu Z, Zhao B, Wang $Y$, Xiao J, Wang $X$ (2020) Composting process and odor emission varied in windrow and trough composting system under different air humidity conditions. Bioresour Technol 297(2):2799-2807

3. Cadena E, Colón J, Sánchez A, Font X, Artola A (2009) A methodology to determine gaseous emissions in a composting plant. Waste Manag 29(11):2799-2807

4. Eitzer BD (1995) Emissions of volatile organic chemicals from municipal solid waste composting facilities. Environ Sci Technol 29(4):896-902

5. Delgado-Rodríguez M, Ruiz-Montoya M, Giraldez I, Cabeza IO, López R, Díaz MJ (2010) Effect of control parameters on emitted volatile compounds in municipal solid waste and pine trimmings composting. J Environ Sci Health A Tox Hazard Subst Environ Eng 45(7):855-862

6. Komilis DP, Ham RK, Park JK (2004) Emission of volatile organic compounds during composting of municipal solid wastes. Water Res 38(7):1707-1714

7. Pierucci P, Porazzi E, Martinez MP, Adani F, Carati C, Rubino FM (2005) Volatile organic compounds produced during the aerobic biological processing of municipal solid waste in a pilot plant. Chemosphere 59(3):423-430

8. Babel S, Fukushi K, Sitanrassamee B (2004) Effect of acid speciation on solid waste liquefaction in an anaerobic acid digester. Water Res 38(9):2416-2422

9. González G, Urrutia H, Roeckel M, Aspé E (2005) Protein hydrolysis under anaerobic, saline conditions in presence of acetic acid. J Chem Technol Biotechnol 80:151-157

10. Nicolas J, Romain AC, Ledent C (2006) The electronic nose as a warning device of the odour emergence in a compost hall. Sensor Actuat B-Chem 116(1/2):95-99

11. Defoer N, De Bo I, Van Langenhove H, Dewulf J, Van Elst T (2002) Gas chromatography-mass spectrometry as a tool for estimating odour concentrations of biofilter effluents at aerobic composting and rendering plants. J Chromatogr A 970(1-2):259-273

12. Scaglia B, Orzi V, Artola A, Font X, Davoli E, Sanchez A, Adani F (2011) Odours and volatile organic compounds emitted from municipal solid waste at different stage of decomposition and relationship with biological stability. Bioresour Technol 102(7):4638-4645

13. Fang JJ, Zhang H, Yang N, Shao LM, He PJ (2013) Gaseous pollutants emitted from a mechanical biological treatment plant for municipal solid waste: odor assessment and photochemical reactivity. J Air Waste Manag Assoc 63(11):1287-1297

14. Tsai CJ, Chen ML, Ye AD, Chou MS, Shen SH, Mao IF (2008) The relationship of odor concentration and the critical components emitted from food waste composting plants. Atmos Environ 42(35):8246-8251

15. Van Thriel C, Schäper M, Kiesswetter E, Kleinbeck S, Juran S, Blaszkewicz M (2006) From chemosensory thresholds to whole body exposuresexperimental approaches evaluating chemosensory effects of chemicals. Int Arch Occup Environ Health 79(4):308-321 
16. Hasanimehr MH, Rad HA, Babaee V (2011) Use of municipal solid waste compost and waste water biosolids with co-composting process. World Appl Sci J 14:60-66

17. USEPA (1999) Compendium method TO-14A, determination of volatile organic compounds (VOCs) in ambient air using specially prepared canisters with subsequent analysis by gas chromatography. Cincinnati, USA

18. Fang JJ, Yang N, Cen DY, Shao LM, He PJ (2012) Odor compounds from different sources of landfill: characterization and source identification. Waste Manag 32(7):1401-1410

19. USEPA (1999) Compendium method TO-11A, determination of formaldehyde in ambient air using adsorbent cartridge followed by high performance liquid chromatography (HPLC). Cincinnati, USA

20. Capelli L, Sironi S, Del Rosso R, Centola P, Grande MA (2008) Comparative and critical evaluation of odor assessment methods on a landfill site. Atmos Environ 42(30):7050-7058

21. USEPA (2019) Integrated risk information system (IRIS). http://www.epa. gov/irisl. Accessed 14 Oct 2021

22. Liu J, Zheng G (2020) Emission of volatile organic compounds from a small-scale municipal solid waste transfer station: ozone-formation potential and health risk assessment. Waste Manag 106:193-202
23. Martí V, Jubany I, Perez C, Rubio X, Pablo JD, Gimenez J (2014) Human health risk assessment of a landfill based on volatile organic compounds emission, immission and soil gas concentration measurements. Appl Geochem 49:218-224

24. Liu Y, Liu Y, Li H, Fu X, Guo H, Meng R (2016) Health risk impacts analysis of fugitive aromatic compounds emissions from the working face of a municipal solid waste landfill in China. Environ Int 97:15-27

25. Wu C, Liu J, Liu S, Li W, Yan L, Shu M (2018) Assessment of the health risks and odor concentration of volatile compounds from a municipal solid waste landfill in China. Chemosphere 202:1-8

26. Bari MA, Kindzierski WB (2017) Concentrations, sources and human health risk of inhalation exposure to air toxics in Edmonton, Canada. Chemosphere 173:160-171

\section{Publisher's Note}

Springer Nature remains neutral with regard to jurisdictional claims in published maps and institutional affiliations.

\section{Submit your manuscript to a SpringerOpen ${ }^{\circ}$ journal and benefit from:}

- Convenient online submission

- Rigorous peer review

- Open access: articles freely available online

- High visibility within the field

- Retaining the copyright to your article

Submit your next manuscript at $\boldsymbol{\nabla}$ springeropen.com 